
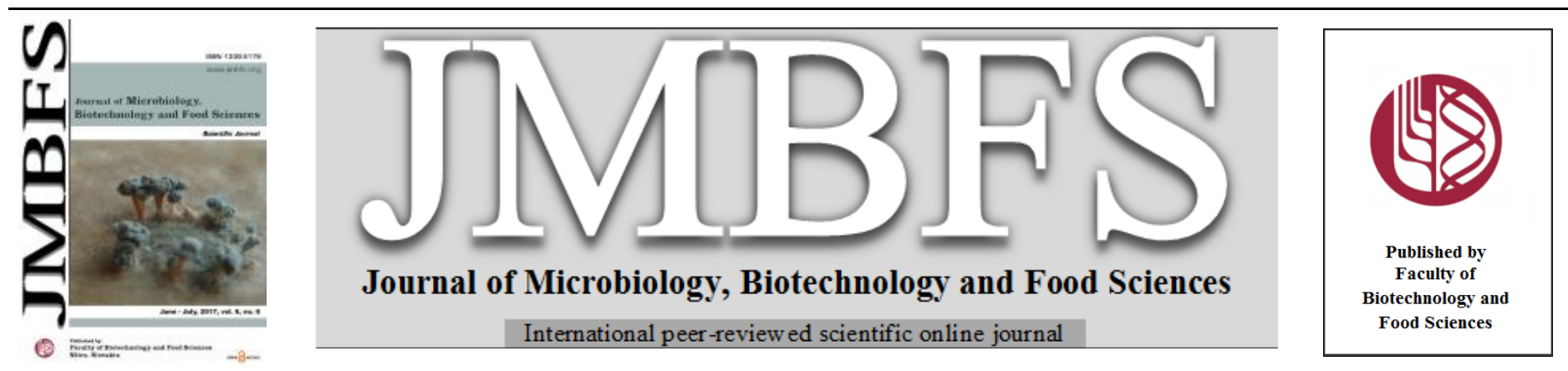

\title{
IN VITRO EFECTS OF SELECTED BIOLOGICALLY ACTIVE COMPOUNDS ON RABBIT SPERMATOZOA MOTILITY BEHAVIOUR
}

\author{
Michal Ďuračka, Marek Halenár, Eva Tvrdá*
}

Address(es): MSc. Eva Tvrdá, PhD.,

Slovak university of Agriculture, Faculty of Biotechnology and Food Sciences, Department of Animal Physiology, Tr. A. Hlinku 2, 94976 Nitra, Slovakia, +421-37641-4918.

*Corresponding author: evina.tvrda@gmail.com

doi: $10.15414 / j m b f s .2017 .6 .6 .1290-1294$

\section{ARTICLE INFO}

Received 7. 3. 2017

Revised 12. 4. 2017

Accepted 16. 5. 2017

Published 1. 6. 2017

Regular article

OPEN $\partial_{\text {ACCESS }}$

\begin{abstract}
The aim of this study was to evaluate the in vitro effects of selected pure naturally occuring biologically active compounds (resveratrolRES, quercetin-QUE, curcumin-CUR, epicatechin-EPI, isoquercitrin-ISO) on rabbit sperm motility using the IDENT staining method and the computer-aided sperm (CASA) analysis. Semen samples were collected regularly from 10 male rabbits, pooled, the seminal plasma was removed and the sperm fraction was exposed to different concentrations $(1,5,10,50$ and $100 \mu \mathrm{mol} / \mathrm{L})$ of chosen biomolecules. At culture times of $0 \mathrm{~h}, 2 \mathrm{~h}, 4 \mathrm{~h}, 6 \mathrm{~h}$ and $8 \mathrm{~h}$, the spermatozoa motility was assessed using the TOX IVOS II. CASA system and the IDENT fluorescent staining method. The motility assessment revealed different behavior patterns, specific and unique to each of the studied biomolecules. After $8 \mathrm{~h}$ of in vitro culture, the highest sperm motility was detected in experimental groups subjected to 10 $\mu \mathrm{mol} / \mathrm{L}$ RES $(\mathrm{P}<0.05) ; 1-10 \mu \mathrm{mol} / \mathrm{L}$ QUE $(\mathrm{P}<0.01$ with respect to $1 \mu \mathrm{mol} / \mathrm{L}$ QUE; $\mathrm{P}<0.001$ in case of 5 and $10 \mu \mathrm{mol} / \mathrm{L}$ QUE); $1 \mu \mathrm{mol} / \mathrm{L}$ CUR (P<0.01); 1-100 $\mu \mathrm{mol} / \mathrm{L}$ EPI $(\mathrm{P}<0.01$ in relation to 50,10 and $5 \mu \mathrm{mol} / \mathrm{L}$ EPI; $\mathrm{P}<0.001$ with respect to 100 and $1 \mu \mathrm{mol} / \mathrm{L}$ EPI) and $10 \mu \mathrm{mol} / \mathrm{L}$ ISO $(\mathrm{P}<0.05)$ when compared to the untreated Control. Our data provide evidence on specific toxic and beneficial concentrations as well as exposure periods applicable for each biomolecule, which may be useful for future in vitro farmagological or toxicological studies on male reproduction in rabbits.
\end{abstract}

Keywords: Spermatozoa, rabbit, resveratrol, quercetin, curcumin, epicatechin, isoquercitrin

\section{INTRODUCTION}

Current evidence suggests that oxidative stress (OS) represents an important factor in male reproductive dysfunction. An increased concentration of abnormal spermatozoa generating free radicals (FRs) and a reduced antioxidant capacity of semen, which has been reported in animals and humans, are two dominant factors underlying seminal OS (Aitken et al., 1991; Tvrdá et al., 2011). At the same time, a specific cellular structure leaves spermatozoa to be uniquely vulnerable to oxidative insults. Sperm plasmatic membranes contain large quantities of polyunsaturated fatty acids, while their cytoplasms lack significant amounts of FR scavengers (Buettner, 1993), leading to an icreased risk of oxidative damage, and subsequently a decreased semen quality (de Lamirande and Gagnon, 1993). Furthermore, FR overproduction may result in increased morphological defects, alterations to sperm capacitation and acrosome reaction, all of which are related to a compromised fertility (Agarwal et al., 2014).

Recently, a number of reports have emphasized on the positive effects of oral antioxidant administration on male fertility in animals and humans (Donnely $\boldsymbol{e} t$ al., 1999; Agarwal and Sekhon, 2010). On the other hand, studies focused on the in vitro effects of antioxidants on spermatozoa are still very sparse, controversial or contradictory. The in vitro data are nevertheless important, as it has been shown on numerous occasions that external antioxidants may protect spermatozoa against oxidative injury and a subsequent dysfunction. Such knowledge is essential for spermatozoa processing protocols performed in medical or veterinary andrology for spermatozoa cryopreservation or assisted reproductive technologies (Saleh and Agarwal, 2002).

Administration of synthetic antioxidants to cell cultures is an efficient strategy to prevent OS. However, the safety of synthetic additives has been under a constant debate, raising the potential of naturally occurring compounds with antioxidant properties because of their chemical diversity, structural complexity, availability, lack of significant toxic effects and intrinsic biologic activity (Alarcón de la Rastra, 2008).

In this study, we followed a systematic approach to assess the in vitro effects of a wide range of pure flavonoid (quercetin, epicatechin, isoquercitrin) and polyphenolic (resveratrol, curcumin) compounds on rabbit sperm motility, one of the physiological manifestations of their fertilizing ability. Furthermore, we have validated the fluorescent-based rabbit sperm motility assessment using the IDENT staining method and the computer-aided sperm (CASA) analysis.

\section{MATERIAL AND METHODS}

Ten male rabbits (New Zealand white broiler line) were used in the experiment. The animals were 4 months old, with a weight of $4.0 \pm 0.2 \mathrm{~kg}$ and kept at an experimental farm of the Animal Production Research Centre Nitra, Slovak Republic. The rabbits were housed in a partially air-conditioned rabbit house under a photoperiod of 16L:8D (a minimum light intensity of $80 \mathrm{lux}$ ), kept in individual cages and fed with a commercial diet. Water was provided ad libitum. The air temperature of $20-24{ }^{\circ} \mathrm{C}$ and relative humidity of $65 \%$ were maintained in the rabbit house. Institutional and national guidelines on the care and use of animals were followed, and all the experimental procedures were approved by the State Veterinary and Food Institute of Slovak Republic (no. 3398/11-221/3) and Ethics Committee.

One ejaculate was collected from each rabbit on a regular collection schedule (twice a week for two consecutive weeks) using an artificial vagina. Immediately upon collection, the sperm concentration and motility were assessed in each ejaculate. Only samples with a minimum motility of $60 \%$ were used in the experiments. Individual ejaculates were mixed together in order to acquire a pooled sample of rabbit semen.

The resulting semen sample was centrifuged $(300 \mathrm{xg})$ at $25^{\circ} \mathrm{C}$ for $5 \mathrm{~min}$, seminal plasma was removed and the sperm pellet was washed twice with PBS (Dulbecco's phosphate-buffered saline without calcium chloride and magnesium chloride; Sigma-Aldrich, St. Louis, MO, USA), resuspended in a culture medium consisting of PBS, 5\% glucose (Centralchem, Bratislava, Slovak Republic) and $4 \%$ BSA (bovine serum albumin, Sigma-Aldrich). Each experimental group was exposed to a different concentration $(1,5,10,50$ and $100 \mu \mathrm{mol} / \mathrm{L})$ of a chosen biomolecule (resveratrol, quercetin, curcumin, epicatechin, isoquercitrin; SigmaAldrich) using a dilution ratio of 1:20. The Control group carried no supplementation. The samples were cultured at $37^{\circ} \mathrm{C}$. 
At culture times of $0 \mathrm{~h}, 2 \mathrm{~h}, 4 \mathrm{~h}, 6 \mathrm{~h}$ and $8 \mathrm{~h}$, the spermatozoa motility (percentage of motile spermatozoa; motility $>5 \mu \mathrm{m} / \mathrm{s} ; \%$ ) was assessed using the computeraided sperm analysis (CASA; Version 14.0 TOX IVOS II.; Hamilton-Thorne Biosciences, Beverly, MA, USA). In order to standardize a fluorescent assessment of sperm activity, the samples were stained using the IDENT stain, a DNA-specific dye based on Hoechst bisbenzimide (Hamilton-Thorne Biosciences). The IDENT dye provided in Eppendorf tube was diluted with $1 \mathrm{~mL}$ of the culture medium and mixed with the sample using a ratio of 1:1. Following a $10 \mathrm{~min}$ incubation in the dark, the sample was analyzed under fluorescent illumination. The system was set up as follows: frame rate - 30 at $60 \mathrm{~Hz}$, dark field; minimum contrast - 50; static head size - 0.28-4.30; static head intensity 0.12-2.92; static elongation - 8-97; minimum cell size -7 pixels; default cell intensity - 70, magnification - 1.75, illumination intensity -2198 . Ten $\mu \mathrm{L}$ of each sample were placed into the Makler counting chamber (depth $10 \mu \mathrm{m}, 37^{\circ} \mathrm{C}$; Sefi Medical Instruments, Haifa, Israel) and immediately assessed. 10 microscopic fields were subjected to each analysis in order to include at least 300 cells.

All the data were subjected to statistical analysis using the GraphPad Prism program (a 3.02 version for Windows, GraphPad Software incorporated, San Diego, California, USA, http://www.graphpad.com/). The results are quoted as the arithmetic mean \pm standard error of mean (SEM). The comparative analysis was carried out by a one-way ANOVA with the Dunnett's post test. The level of significance for the analysis was set at ${ }^{*} \mathrm{P}<0.05 ;{ }^{* *} \mathrm{P}<0.01 ;{ }^{* * *} \mathrm{P}<0.001$.

\section{RESULTS AND DISCUSSION}

\section{Resveratrol (RES)}

The CASA assessment revealed a continuous decrease of spermatozoa motility and in all groups over the course of a $8 \mathrm{~h}$ in vitro culture (Table 1 ). The initial (Time 0h) MOT was higher in the experimental groups supplemented with 5 and $50 \mu \mathrm{mol} / \mathrm{L}$ RES when compared to the Control group, although without any statistical significance $(\mathrm{P}>0.05)$. Despite being statistically insignificant, a motion-promoting effect of RES remained notable after $2 \mathrm{~h}$, specifically following the addition of 1,5 and $50 \mu \mathrm{mol} / \mathrm{L}$ RES. A significantly higher $(\mathrm{P}<0.05) \mathrm{MOT}$ was detected in case of 1 and $5 \mu \mathrm{mol} / \mathrm{L}$ RES following a $4 \mathrm{~h}$ culture. After $6 \mathrm{~h}$, the decline of spermatozoa MOT was significantly slowed down following the supplementation of a concentration range of $1-10 \mu \mathrm{mol} / \mathrm{L}$ RES $(\mathrm{P}<0.001)$. At the end of the experiment $(8 h)$, elevated motility was observed in the experimental group supplemented with $5 \mu \mathrm{mol} / \mathrm{L}$ RES, being significantly higher in comparison with the Control $(\mathrm{P}<0.05)$ (Table 1$)$

Table 1 Time- and dose-dependent effects of resveratrol (RES) on rabbit spermatozoa motility [\%]

\begin{tabular}{|c|c|c|c|c|c|c|}
\hline & Ctrl & $100 \mu \mathrm{mol} / \mathrm{L}$ RES & $50 \mu \mathrm{mol} / \mathrm{L}$ RES & $10 \mu \mathrm{mol} / \mathrm{L}$ RES & $5 \mu \mathrm{mol} / \mathrm{L}$ RES & $1 \mu \mathrm{mol} / \mathrm{L}$ RES \\
\hline $\mathbf{0 h}$ & $80.55 \pm 2.33$ & $68.97 \pm 6.59$ & $81.90 \pm 8.21$ & $73.98 \pm 5.55$ & $82.98 \pm 8.32$ & $73.95 \pm 6.87$ \\
\hline $2 \mathrm{~h}$ & $69.03 \pm 4.02$ & $61.09 \pm 7.00$ & $72.99 \pm 6.98$ & $69.09 \pm 4.76$ & $78.99 \pm 7.89$ & $73.56 \pm 8.00$ \\
\hline $4 h$ & $59.12 \pm 3.33$ & $53.98 \pm 4.44$ & $58.90 \pm 6.09$ & $68.89 \pm 3.44$ & $73.98 \pm 6.02 *$ & $69.98 \pm 5.99 *$ \\
\hline $6 h$ & $37.55 \pm 2.99$ & $43.98 \pm 3.99$ & $46.97 \pm 3.98$ & $56.09 \pm 5.55^{* *}$ & $63.79 \pm 5.96 * * *$ & $60.98 \pm 5.99 * * *$ \\
\hline $8 h$ & $20.04 \pm 1.88$ & $11.98 \pm 2.09$ & $15.04 \pm 0.67$ & $14.90 \pm 1.23$ & $29.99 \pm 2.09^{*}$ & $23.19 \pm 2.00$ \\
\hline
\end{tabular}

RES has recently emerged as a complex biomolecule due to its wide range of cardiovascular, anticancer, antiinflamatory and protective effects (Calabrese $\boldsymbol{e}$ al., 2010). Although no distinct toxicity was reported in vivo (Cottart et al. 2010), in vitro experiments show that low RES doses improve cell survival, while high doses increase cell death (Brown et al., 2009).

Our CASA results are contradictory to Collodel et al. (2010) who evaluated the effects of RES on human spermatozoa. Unlike our results, $100 \mu \mathrm{mol} / \mathrm{L}$ RES exerted cytotoxic activities against spermatozoa in a dose dependent manner. The LD50 was defined as $50 \mu \mathrm{mol} / \mathrm{L}$ RES, spermatocytes were more sensitive to the harmful effect of RES with a LD50 between 30 and $50 \mu \mathrm{mol} / \mathrm{L}$. While at 100 $\mu \mathrm{mol} / \mathrm{L}$ RES the rabbit sperm motility was decreased in a non-significant manner, human sperm motility in the above mentioned study was absent. Moreover, Tvrdá et al. (2015b) reported a significant decrease of bull sperm motility following exposure to 100 or $200 \mu \mathrm{mol} / \mathrm{L}$ RES during a 24 in vitro culture. The differences in our results may be explained by the sample type which was collected from rabbits as opposed to humans or bulls respectively, as well as a shorter exposure to the biocompound. On the other hand, the stimulating effects of lower (1-5 $\mu \mathrm{mol} / \mathrm{L})$ RES concentrations detected by our IDENT CASA technique are in agreement with Tvrdá et al. (2015a;b) who emphasize on the beneficial and protective effects of a concentration range of 5-50 $\mu \mathrm{mol} / \mathrm{L}$ RES on the motion behavior, mitochondrial activity and intracellular superoxide production by bovine sperm cells. Furthermore, in an in vitro human study, progressive motility reached high values between 6 and $15 \mu \mathrm{mol} / \mathrm{L}$ RES (Collodel et al., 2010).

Our CASA records are in agreement with Mojica-Villegas et al. (2014) who reported that a pretreatment with $15 \mu \mathrm{mol} / \mathrm{L}$ RES $15 \mathrm{~min}$ prior to incubation with ferrous ascorbate (FeAA) showed an 8.0-fold increase in murine spermatozoa motility. On the other hand, spermatozoa motility diminished in spermatozoa cryopreserved with RES comparably to the control in the studies by Pasqualotto et al. (2006) and Garcez et al. (2010) Furthermore Silva et al. (2012) reported that the addition of RES before cryopreservation did not significantly affect progressive motility, vigor, acrosome integrity, or plasma membrane integrity. In the meantime, Sarlos et al. (2002) recorded a higher motility and acrosome integrity of ram spermatozoa supplemented with RES after their storage at $5 \mathrm{C}$ for 6 days. Similar results were reported in studies focused on swim-up selected human spermatozoa where low RES doses led to a higher progressive motility (Collodel et al., 2010).

\section{Quercetin (QUE)}

The CASA examination revealed an immediate (Time 0h) but insignificant $(\mathrm{P}>0.05)$ motion-promoting effect of QUE, specifically in experimental groups exposed to 1 and $10 \mu \mathrm{mol} / \mathrm{L}$ of this flavonoid (Table 2). Beneficial effects of QUE remained visible although non-significant $(\mathrm{P}>0.05)$ at Time $2 \mathrm{~h}$, and covering all the concentrations applied to the experimental groups. After $4 \mathrm{~h}$, spermatozoa motion was significantly higher in the experimental groups supplemented with 1, $5(\mathrm{P}<0.05)$ and $100(\mathrm{P}<0.01) \mu \mathrm{mol} / \mathrm{L}$ QUE. Nevertheless, motility evalution at $6 \mathrm{~h}$ revealed a rapid decline of rabbit sperm motion exposed to the highest QUE concentration, resulting in a significantly lower MOT in comparison with the Control $(\mathrm{P}<0.01)$. At the same time, sperm motility promoting properties of low QUE concentrations were confirmed, leading to a higher MOT $(\mathrm{P}<0.001$ in relation to $1 \mu \mathrm{mol} / \mathrm{L}$ QUE; $\mathrm{P}<0.05$ with respect to 5 $\mu \mathrm{mol} / \mathrm{L}$ QUE; Table 2) when compared to the Control. At the end of the experiment (8h), a significantly higher spermatozoa MOT was observed in experimental groups supplemented with a range of $1-10 \mu \mathrm{mol} / \mathrm{L}$ QUE $(\mathrm{P}<0.01$ with respect to $1 \mu \mathrm{mol} / \mathrm{L}$ QUE; $\mathrm{P}<0.001$ in case of 5 and $10 \mu \mathrm{mol} / \mathrm{L}$ QUE) Meanwhile, the MOT assessment revealed a decreased bias in the experimental group supplemented with the highest concentration of QUE $(100 \mu \mathrm{mol} / \mathrm{L})$, after a comparison with the Ctrl group $(\mathrm{P}<0.001)$.

Table 2 Time- and dose-dependent effects of quercetin (QUE) on rabbit spermatozoa motility [\%]

\begin{tabular}{ccccccc}
\hline & $\mathbf{C t r l}$ & $\mathbf{1 0 0} \boldsymbol{\mu \mathbf { m o l } / \mathbf { L } \text { QUE }}$ & $\mathbf{5 0} \boldsymbol{\mu \mathbf { m o l } / \mathbf { L } \text { QUE }}$ & $\mathbf{1 0} \boldsymbol{\mu \mathbf { m o l } / \mathbf { L } \mathbf { Q U E }}$ & $\mathbf{5} \boldsymbol{\mu \mathbf { m o l } / \mathbf { L } \mathbf { Q U E }}$ & $\mathbf{1} \boldsymbol{\mu \mathbf { m o l } / \mathbf { L } \text { QUE }}$ \\
\hline $\mathbf{0 h}$ & $80.55 \pm 2.33$ & $76.16 \pm 6.09$ & $79.98 \pm 5.55$ & $80.80 \pm 9.01$ & $77.55 \pm 3.23$ & $81.45 \pm 2.90$ \\
$\mathbf{2 h}$ & $69.03 \pm 4.02$ & $74.55 \pm 4.55$ & $77.34 \pm 3.99$ & $77.77 \pm 6.09$ & $74.23 \pm 2.90$ & $77.64 \pm 3.39$ \\
$\mathbf{4 h}$ & $59.12 \pm 3.33$ & $73.22 \pm 3.99^{* *}$ & $68.09 \pm 5.22$ & $67.67 \pm 5.02$ & $73.89 \pm 3.22^{*}$ & $72.76 \pm 4.44^{*}$ \\
$\mathbf{6 h}$ & $37.55 \pm 2.99$ & $16.90 \pm 1.20^{* *}$ & $20.90 \pm 3.33$ & $29.12 \pm 2.31$ & $47.66 \pm 1.99^{*}$ & $60.77 \pm 4.44^{* * *}$ \\
$\mathbf{8 h}$ & $20.04 \pm 1.88$ & $9.09 \pm 0.35^{* * *}$ & $18.07 \pm 1.77$ & $41.21 \pm 2.33^{* * *}$ & $42.24 \pm 2.12^{* * *}$ & $39.03 \pm 2.22^{* *}$ \\
\hline Mea
\end{tabular}

Quercetin is a common dietary flavonoid, reported to exhibit a broad variety of favorable biological effects (Aherne and O'Brien, 2000), hence it is not a surprise to find reports focused on assessing its impact on male reproductive performance.

Improved motility recorded after QUE administration to the rabbit sperm medium in our study disagrees with earlier reports, according to which QUE compromised human sperm motility (at 5-200 $\mu \mathrm{mol} / \mathrm{L}$ QUE) and viability $(50-100 \mu \mathrm{mol} / \mathrm{L}$ QUE), coinciding with $\mathrm{Ca}^{2+}$-ATPase downregulation, and leading to the loss of sperm motion (Khanduja et al., 2001). In addition, this biomolecule exhibited a significant inhibitory impact on the hyaluronidase activity and sperm penetration ability of non-capacitated, capacitated and acrosome-reacted Cynomolgus monkey sperm in a dose-dependent manner (Li et al., 1997). Talking in favor of 
our results, Tvrdá et al. $(2014 ; \mathbf{2 0 1 6 b})$ did suggest protective effects of QUE on bovine sperm motion activity when incubated over a period of $24 \mathrm{~h}$ (Tvrdá $\boldsymbol{e t}$ al. 2014) or without the presence of seminal plasma (Tvrdá et al., 2016), although we must acknowledge that in case of a broader concentration range, QUE may act dose dependently as either a stimulant at low concentrations or as an inhibitor at high doses (Taepongsorat et al., 2008). This controversy was validated in vivo when Aravindakshan et al. (1985) revealed that treatment with higher QUE doses $(300 \mathrm{mg} / \mathrm{kg}$ body weight) reduced the fertility rate of male rats, while Taepongsorat et al. (2008) showed that intramuscular administration of 90 and $270 \mathrm{mg}$ QUE/kg body weight/day led to significant improvements in the spermatozoa concentration, motility and viability.

Mazzi et al. (2011) and Moretti et al. (2012) compared the potential of quercetin and resveratrol on human sperm incubated with tert-butylhydroperoxide (TBHP) On the one hand, QUE showed a higher toxicity with respect to the sperm motility and viability than RES, and on the other hand, its antioxidant activity was stronger, as evidenced by fluorescent and electron microscopy. QUE was particularly active in preserving sperm membranes, chromatin texture and acrosomes, which were compromised by TBHP. Similarly, Tvrdá et al. (2016b) found that QUE was capable of preventing the decline of spermatozoa vitality and functional activity as a consequence of FeAA-associated oxidative damage. Quercetin concentrations ranging between 50 and $100 \mu \mathrm{mol} / 1$ were particularly effective in protecting the spermatozoon against the damage caused by free radical overgeneration through prevention of lipid peroxidation, protection and maintenance of spermatozoa metabolism as reflected by the motility and mitochondrial activity.

\section{Curcumin (CUR)}

In case of CUR, the MOT evaluation revealed that the initial (Time 0h) MOT was higher in experimental groups supplemented with 5 and $100 \mu \mathrm{mol} / \mathrm{L}$ CUR when compared to the Control group $(0 \mu \mathrm{mol} / \mathrm{L}$ CUR $)$, although without any statistical significance $(\mathrm{P}>0.05)$. Although statistically insignificant, a motionpromoting effect of CUR was visible after $2 \mathrm{~h}$, specifically in experimental groups exposed to 5 and $10 \mu \mathrm{mol} / \mathrm{L}$ CUR. At the same time, 50 and $100 \mu \mathrm{mol} / \mathrm{L} \mathrm{CUR}$ caused a significant decrease of the spermatozoa motility $(\mathrm{P}<0.001)$. After $4 \mathrm{~h}$, the decline of spermatozoa motion was significantly decreased following the administration of 50 and $100 \mu \mathrm{mol} / \mathrm{L}$ CUR in comparison with the Control Furthermore, a significantly increased sperm MOT was observed in experimental groups supplemented with $1,5(\mathrm{P}<0.01)$ and $10 \mu \mathrm{mol} / \mathrm{L}$ CUR $(\mathrm{P}<0.05)$ Examination at $6 \mathrm{~h}$ of in vitro culture showed that the spermatozoa motility was significantly increased following exposure to 1 and $5 \mu \mathrm{mol} / \mathrm{L}$ CUR $(\mathrm{P}<0.001)$ when compared to the Control. At the same time, an insignificantly higher (P>0.05) motion was recorded in the group supplemented with $10 \mu \mathrm{mol} / \mathrm{L}$ CUR, while a significant $(\mathrm{P}>0.001)$ decline was observed in the case of 50 and 100 $\mu \mathrm{mol} / \mathrm{L}$ CUR. At the end of the experiments $(8 \mathrm{~h})$, the highest motility was observed in the experimental group supplemented with $1 \mu \mathrm{mol} / \mathrm{L}$ CUR, being significantly higher in comparison with the Control $(\mathrm{P}<0.01)$, while MOT was significantly decreased $(\mathrm{P}<0.001)$ in the groups supplemented by the highes concentrations of CUR, after a comparison with the Ctrl group $(\mathrm{P}<0.001$; Table 3).

Table 3 Time- and dose-dependent effects of curcumin (CUR) on rabbit spermatozoa motility [\%]

\begin{tabular}{|c|c|c|c|c|c|c|}
\hline & Ctrl & $100 \mu \mathrm{mol} / \mathrm{L} \mathrm{CUR}$ & $50 \mu \mathrm{mol} / \mathrm{L} \mathrm{CUR}$ & $10 \mu \mathrm{mol} / \mathrm{L} \mathrm{CUR}$ & $5 \mu \mathrm{mol} / \mathrm{L} \mathrm{CUR}$ & $1 \mu \mathrm{mol} / \mathrm{L} \mathrm{CUR}$ \\
\hline $\mathbf{0 h}$ & $80.55 \pm 2.33$ & $82.31 \pm 7.56$ & $77.88 \pm 6.78$ & $79.98 \pm 6.77$ & $85.98 \pm 5.98$ & $75.33 \pm 5.32$ \\
\hline $2 \mathrm{~h}$ & $69.03 \pm 4.02$ & $0.00 \pm 0.00^{* * * *}$ & $44.45 \pm 3.33^{* * *}$ & $76.77 \pm 7.07$ & $78.86 \pm 4.44$ & $75.65 \pm 3.33$ \\
\hline $4 h$ & $59.12 \pm 3.33$ & $0.00 \pm 0.00^{* * *}$ & $26.24 \pm 2.11^{* * *}$ & $70.09 \pm 5.55^{*}$ & $74.98 \pm 6.08^{* *}$ & $75.77 \pm 4.67^{* *}$ \\
\hline $6 h$ & $37.55 \pm 2.99$ & $0.00 \pm 0.00^{* * *}$ & $1.09 \pm 0.09^{* * *}$ & $42.43 \pm 3.99$ & $74.57 \pm 5.45^{* * *}$ & $57.87 \pm 5.78^{* * * *}$ \\
\hline $\mathbf{8 h}$ & $20.04 \pm 1.88$ & $0.00 \pm 0.00^{* * * *}$ & $0.00 \pm 0.00^{* * * *}$ & $17.56 \pm 1.90$ & $17.90 \pm 2.02$ & $37.09 \pm 1.11^{* *}$ \\
\hline
\end{tabular}

Previous reports on the impact of CUR on male fertility are debatable. Naz (2011) revealed that exposure of human and murine sperm to CUR caused a concentration-dependent decrease of sperm motility, capacitation and acrosome reaction. At high CUR concentrations, a complete inhibiton of spermatozoa motility and function was observed. Studies on the impact of CUR on the spermatozoa activity have indicated its role in the energy metabolism of male reproductive cells. Reddy and Aggarwal (1994) suggest that CUR has the ability to inhibit protein kinase $\mathrm{C}$ ( $\mathrm{PKC})$, which is believed to have a role in modulating spermatozoa flagellar movement (Rotem et al., 1990a,b). As such, the CUR induced PKC inhibition may be responsible for its possible spermatozoaimmobilizing activities (Rithaporn et al., 2003). On the other hand, our results agree with Salashoor et al. (2012) and Tvrdá et al. (2016b) suggesting stimulating and protective effects of CUR on spermatozoa motility and antioxidant status. Moreover Salashoor et al. (2012) reported that increasing doses of CUR significantly increased the sperm concentration, motility and testosterone content in rats.

The first report on the useful effects of CUR (Bucak $\boldsymbol{e t}$ al., 2008) on the motility, morphology and antioxidant activities of cooled ram spermatozoa has given rise to its use as an antioxidant additive to the freezing extender. Motility parameters recorded by our IDENT CASA technique complement previous findings by Bucak et al. (2008; 2010) demonstrating a significant improvement in the motion of cryopreservad ram spermatozoa supplemented with CUR. Interestingly, their later study focused on CUR administration to a cryopreservation extender for bovine semen led to non-significant differences in the sperm motion characteristics (Bucak et al., 2012). Nevertheless, our results correlate with the report by Soleimanzadeh and Saberivand (2013) as well as Tvrda et al. (2016c) on frozen-thawed semen, where CUR addition had a positive impact on both motility and viability.

\section{Epicatechin (EPI)}

In the case of EPI, the initial MOT assessment (Time 0h) revealed a nonsignificantly increased sperm motion in all experimental groups supplemented with EPI (P>0.05) in comparison to the Control group (Table 4). After $2 \mathrm{~h}$, a significant motion-promoting effect was noted in case of $1 \mu \mathrm{mol} / \mathrm{L}$ and 50 $(\mathrm{P}<0.01) \mu \mathrm{mol} / \mathrm{L}$ EPI $(\mathrm{P}<0.001)$. This beneficial effect remained visible after $4 \mathrm{~h}$ and furthermore included a broader concentration range when compared to the Control $(\mathrm{P}<0.05$ with respect to $50 \mu \mathrm{mol} / \mathrm{L} \mathrm{EPI;} \mathrm{P}<0.01$ in terms of 100 and 5 $\mu \mathrm{mol} / \mathrm{L}$ EPI; $\mathrm{P}<0.001$ in case of $1 \mu \mathrm{mol} / \mathrm{L} \mathrm{EPI).} \mathrm{After} 6 \mathrm{~h}$, the decline of MOT associated with the in vitro culture was slowed down significantly in al experimental groups exposed to EPI $(\mathrm{P}<0.05$ with respect to $5 \mu \mathrm{mol} / \mathrm{L} \mathrm{EPI}$ $\mathrm{P}<0.001$ in case of $100,50,10$ and $1 \mu \mathrm{mol} / \mathrm{L} \mathrm{EPI}$ ), and this MOT-stimulating and protective effect extended throughout the end of the in vitro experiment (Time $8 \mathrm{~h} ; \mathrm{P}<0.01$ in relation to 50,10 and $5 \mu \mathrm{mol} / \mathrm{L}$ EPI; $\mathrm{P}<0.001$ with respect to 100 and $1 \mu \mathrm{mol} / \mathrm{L} \mathrm{EPI)}$

Table 4 Time- and dose-dependent effects of epicatechin (EPI) on rabbit spermatozoa motility [\%]

\begin{tabular}{|c|c|c|c|c|c|c|}
\hline & Ctrl & $100 \mu \mathrm{mol} / \mathrm{L} \mathrm{EPI}$ & $50 \mu \mathrm{mol} / \mathrm{L}$ EPI & $10 \mu \mathrm{mol} / \mathrm{L} \mathrm{EPI}$ & $5 \mu \mathrm{mol} / \mathrm{L}$ EPI & $1 \mu \mathrm{mol} / \mathrm{L} \mathrm{EPI}$ \\
\hline $\mathbf{O h}$ & $80.55 \pm 2.33$ & $83.89 \pm 8.01$ & $80.77 \pm 7.65$ & $81.98 \pm 7.43$ & $80.98 \pm 7.89$ & $83.24 \pm 67$ \\
\hline $2 h$ & $69.03 \pm 4.02$ & $75.67 \pm 7.07$ & $80.08 \pm 6.78^{* *}$ & $76.77 \pm 5.67$ & $77.09 \pm 5.09$ & $82.76 \pm 7.77^{* * * *}$ \\
\hline $4 h$ & $59.12 \pm 3.33$ & $74.67 \pm 4.78^{* *}$ & $73.56 \pm 8.00^{*}$ & $68.65 \pm 3.21$ & $76.67 \pm 6.56^{* *}$ & $80.98 \pm 8.00^{* * * *}$ \\
\hline $6 h$ & $37.55 \pm 2.99$ & $72.22 \pm 6.65^{* * *}$ & $60.97 \pm 5.56^{* * *}$ & $58.46 \pm 4.44^{* * *}$ & $49.79 \pm 3.67^{*}$ & $73.98 \pm 7.44^{* * * *}$ \\
\hline $8 h$ & $20.04 \pm 1.88$ & $42.77 \pm 3.33^{\text {**** }}$ & $36.09 \pm 6.07^{* *}$ & $38.98 \pm 3.87^{* * *}$ & $38.33 \pm 2.99^{* *}$ & $40.48 \pm 7.09^{* * *}$ \\
\hline
\end{tabular}

Epicatechin is a flavonoid and antioxidant commonly found in green tea and, most of all, in cocoa (Katz et al., 2011). Since it is known that spermatozoa are sensitive to OS, several studies have examined potential roles of in vitro EP supplementation in protecting sperm from ROS overproduction. Jamalan $\boldsymbol{e t}$ al. (2016) evaluated the effects of different flavonoids including EPI on the recovery of sperm motility and prevention of membrane damage from aluminum chloride, cadmium chloride, and lead chloride. The study revealed that catechin behaved in an unexpected manner as it did not protect spermatozoa from heavy metalmediated damage, nor it did not exhibit any protective effects, rather, it showed inhibitory effects on the sperm MOT associated with a co-incubation with selected heavy metals. Following the application of increased catechin concentrations from 0 to $1000 \mu \mathrm{mol} / \mathrm{L}$, a gradual and dose-dependent decrease in sperm motility compared to the untreated control group was observed. Similarly, Moretti et al. (2012) showed that none of the selected EPI concentrations selected $(20,30,50,100,200,400 \mu \mathrm{mol} / \mathrm{L})$ was not effective as an antioxidant to protect swim-up selected human sperm against tert-butylhydroperoxide induced lipid peroxidation. Furthermore, the study showed that sperm progressive motility and viability were significantly reduced after incubation with EPI at 400 
$\mu \mathrm{mol} / \mathrm{L}$. Recently, differential protective effects of epicatechin gallate against induced mitochondrial dysfunction were explored in intestinal epithelial Caco-2 cells and even in this case no protection was observed (Carrasco-Pozo et al., 2011).

On the contrary to the above mentioned studies our results revealed stimulating effects of all EPI concentrations on the motility behavior following its supplementation to rabbit spermatozoa. Such data are in agreement with Purdy $\boldsymbol{e}$ al. (2004) who aimed to determine whether supplementing diluents with catechin, would aid in maintaining the viability of caprine sperm during cooling and storage at $5{ }^{\circ} \mathrm{C}$. The study revealed significant differences $(\mathrm{P}<0.05)$ in motility between the control (34\%) and the $25,50,75$ and $100 \mu \mathrm{mol} / \mathrm{L}$ concentrations of catechin (57, 53, 55 and $64 \%$ motile cells, respectively) at 96h. These results demonstrated that catechin may aid in maintaining the motility of cooled goat sperm in a dose dependent manner.

\section{Isoquercitrin (ISO)}

According to the CASA analysis the initial MOT (Time 0h) was insignificantly increased in experimental groups subjected to treatment with 1,5 and $50 \mu \mathrm{mol} / \mathrm{L}$ ISO when compared to the Control (Table 5). This non-significant but motility- promoting effect of 1, 5, 50 and $100 \mu \mathrm{mol} / \mathrm{L}$ ISO remained notable after $2 \mathrm{~h}$ of in vitro culture. After $4 \mathrm{~h}$, a significantly higher MOT was recorded in the group exposed to $5 \mu \mathrm{mol} / \mathrm{L}$ ISO when compared to the Control $(\mathrm{P}<0.01)$. At $6 \mathrm{~h}$ the spectrum of ISO concentrations exhibiting beneficial effects on the sperm motility expanded, as a significantly higher MOT was recorded in groups administered with 1, 5, $10(\mathrm{P}<0.05)$ and $50 \mu \mathrm{mol} / \mathrm{L}$ ISO $(\mathrm{P}<0.001)$. Nevertheless, at the end of the in vitro culture, a significantly higher MOT was detected in the experimental group supplemented with $10 \mu \mathrm{mol} / \mathrm{L}$ ISO $(\mathrm{P}<0.05)$ when compared to the Control. Interestingly, a notble however non-significant $(\mathrm{P}>0.05)$ decrase of sperm MOT was recorded following exposure to the highest ISO concentration (100 $\mu \mathrm{mol} / \mathrm{L}$ ISO). Administration of the rest of the selected concentrations led to an insignificantly higher rabbit sperm MOT $(\mathrm{P}>0.05)$ in comparison with the Control (Table 5).

Table 5 Time- and dose-dependent effects of isoquercitrin (ISO) on rabbit spermatozoa motility [\%]

\begin{tabular}{ccccccc}
\hline & $\mathbf{C t r l}$ & $\mathbf{1 0 0} \boldsymbol{\mu \mathbf { m o l } / \mathbf { L } \text { ISO }}$ & $\mathbf{5 0} \boldsymbol{\mu \mathbf { m o l } / \mathbf { L } \text { ISO }}$ & $\mathbf{1 0} \boldsymbol{\mu \mathbf { m o l } / \mathbf { L } \text { ISO }}$ & $\mathbf{5} \boldsymbol{\mu m o l} / \mathbf{L}$ ISO & $\mathbf{1} \boldsymbol{\mu m o l} / \mathbf{L}$ ISO \\
\hline $\mathbf{0 h}$ & $80.55 \pm 2.33$ & $79.89 \pm 6.67$ & $81.98 \pm 7.99$ & $79.56 \pm 4.90$ & $84.89 \pm 9.02$ & $81.99 \pm 7.02$ \\
$\mathbf{2 h}$ & $69.03 \pm 4.02$ & $76.77 \pm 4.42$ & $76.56 \pm 6.01$ & $67.97 \pm 5.09$ & $77.87 \pm 7.02$ & $76.54 \pm 4.01$ \\
$\mathbf{4 h}$ & $59.12 \pm 3.33$ & $63.54 \pm 5.09$ & $67.87 \pm 5.55$ & $66.67 \pm 6.09$ & $76.87 \pm 6.98^{* *}$ \\
$\mathbf{6 h}$ & $37.55 \pm 2.99$ & $44.87 \pm 3.99$ & $48.35 \pm 4.78^{*}$ & $73.78 \pm 8.00^{* * *}$ & $73.77 \pm 4.78^{* * *}$ \\
$\mathbf{8 h}$ & $20.04 \pm 1.88$ & $11.09 \pm 1.89$ & $20.09 \pm 1.98$ & $30.99 \pm 4.09^{*}$ & $21.34 \pm 2.06$ \\
\hline
\end{tabular}

Isoquercitrin is found in foods such as apple and onion, as well as in a variety of medicinal plants, likely contributing to the pharmacological qualities of a large number of botanical medicines. Some of the most commonly used plants containing these flavonoids include Horse chestnut, Ginkgo, Horsetail, Fennel, Rooibos, Hops, Sundew, Bilberry and Mulberry (Dok-Go et al., 2003; Appleton, 2010). ISO is one of the naturally occurring glucosides of quercetin. Isoquercitrin is also sometimes called isoquercetin, a nearly identical quercetin-3monoglucoside. Technically the two are different (isoquercetin has a pyranose ring whereas isoquercitrin has a furanose ring), but functionally the two molecules are indistinguishable. The literature often considers them as one and uses the names interchangeably (Appleton, 2010). To our knowledge, no study is currently available on the impact of isoquerctrin on male reproduction. According to our data, although being structurally similar to QUE, the molecule did not exhibit significant negative effects on the sperm MOT when compared to QUE. On the other hand, potential beneficial effects of lower concentrations of ISO were less notable and significant in comparison with QUE. Although experiments based on the administration of pure ISO have not been done yet, numerous animal studies emphasize on potential ameliorative and antioxidant effect of plant extracts containing ISO on the testicular structure and function, as well as sperm concentration, motility and morphology in sickness and health (Awoniyi et al., 2011; Ayeleso et al., 2014; Ďuračka et al., 2016). As such, we may suggest that more specific experiments on the roles of ISO are to be done in the future in order to elucidate its beneficial and/or harmful roles in male reproduction.

\section{CONCLUSION}

A relatively broad spectrum of positive as well as negative effects has been linked to the treatment of individual biologically active compounds in experimental in vitro and in vivo models. Their mechanisms of action have only recently started to be uncovered, particularly in relation to male reproduction. Our study has unraveled a specific behavior of each biomolecule, providing evidence on their toxic and beneficial concentrations as well as exposure periods adequate for the exhibition of their protective or harmful impact on rabbit sperm survival.

Identification of a normal physiological range of biologically active compound and their metabolites in mammalian tissues is of utmost importance if researchers aim to determine if the effects observed with respect to a certain dose are physiologically relevant. Furthermore, determining the clinical relevance of results obtained from animal or in vitro studies may be difficult as these studies often use doses which may exceed physiological concentrations. As such, these aspects must be taken into account in the design of future experimental studies, irrespective of whether they are aimed at evaluating beneficial or adverse effects of natural biomolecules.
Acknowledgments: This research is a part of project supported by the Research Center AgroBioTech built in accordance with the project Building Research Centre "AgroBioTech" ITMS 26220220180 and by the Slovak Research and Development Agency Grants no. APVV- 0304-12 and APVV-15-0544.

\section{REFERENCES}

Agarwal, A. \& Sekhon, L. (2010). The role of antioxidant therapy in the treatment of male infertility. Human Fertility, 13(4), 217-225. http://dx.doi.org/10.3109/14647273.2010.532279.

Agarwal, A., Tvrda, E. \& Sharma, R. (2014). Relationship amongst teratozoospermia, seminal oxidative stress and male infertility. Reproductive Biology and Endocrinology, 12, 45. http://dx.doi.org/10.1186/1477-7827-12-45. Aherne, S.A. \& O'Brien, N.M. (2000). Mechanism of protection by the flavonoids, quercetin and rutin, against tert-butylhydroperoxide- and menadioneinduced DNA single strand breaks in Caco-2 cells. Free Radicals in Biology and Medicine, 29, 507-514. http://dx.doi.org/10.1016/S0891-5849(00)00360-9.

Aitken, R. J., Irvine, D. S. \& Wu, F. C. (1991). Prospective analysis of spermoocyte fusion and reactive oxygen species generation as criteria for the diagnosis of infertility. American Journal of Obstetrics and Gynecology, 164, 542-551. https://doi.org/10.1016/S0002-9378(11)80017-7.

Alarcón de la Rastra, C. (2008). Curcumin: a promising spice for therapeutics Molecular Nutrition \& Food Research, 52, 985. http://dx.doi.org/10.1002/mnfr.200890036.

Appleton, J. (2010). Evaluating the bioavailability of isoquercetin. Natural Medicine Journal, 2(1), 1-4

Aravindakshan, M., Chauhan, P.S. \& Sundaram, K. (1985). Studies on germinal effects of quercetin, a naturally occurring flavonoid. Mutation Research, 144 99-106.

Awoniyi, D.O., Aboua, Y.G., Marnewick, J.L., du Plesis, S.S. \& Brooks, N.L (2011). Protective effects of rooibos (Aspalathus linearis), green tea (Camellia sinensis) and commercial supplements on testicular tissue of oxidative stress induced rats. African Journal of Biotechnology, 10(75), 17317-17322 http://dx.doi.org/10.5897/AJB11.2210.

Ayeleso, A.O., Oguntibeju, O.O., Aboua, Y.G. \& Brooks, N.L. (2014). Effects of red palm oil and rooibos on sperm motility parameters in streptozotocin-induced diabetic rats. African Journal of Traditional, Complementary, and Alternative Medicines, 11(5), 8-15.

Brown, L., Kroon, P.A., Das, D.K., Das, S., Tosaki, A. \& Chan, V. (2009). The biological responses to resveratrol and other polyphenols from alcoholic beverages. Alcoholism: Clinical \& Experimental Research, 33, 1513- 23 http://dx.doi.org/10.1158/0008-5472.

Bucak, M.N., Atessahin, A. \& Yuce, A. (2008). Effect of anti-oxidants and oxidative stress parameters on ram semen after the freeze-thawing process. Small
Ruminant
Research,
75 ,
$128-134$

http://dx.doi.org/10.1016/j.cryobiol.2010.09.001

Bucak, M.N., Sariozkan, S., Tuncer, P.B., Sakin, F., Atessahin, A., Kulaksız, R. \& Cevik, M. (2010). The effect of antioxidants on post-thawed Angora goat (Capra hircus ancryrensis) sperm parameters, lipid peroxidation and antioxidan 
activities. Small Ruminant Research, 89, 24-30. http://dx.doi.org/10.1016/j.smallrumres.2009.11.015.

Bucak, M.N., Basspinar, N., Tuncer, B.P., Coyan, K., Sariozkan, S., Akalin, P.P. \& Buyukleblebici, S., Kucukgunay, S. (2012). Effects of curcumin and dithioerythritol on frozen-thawed bovine semen. Andrologia, 44, 102-109. http://dx.doi.org/10.1111/j.1439-0272.2010.01146.x.

Buettner, G. R. (1993). The pecking order of free radicals and antioxidants: lipid peroxidation, alpha-tocopherol and ascorbate. Archives of Biochemistry and Biophysics, 300, 535-543.

Calabrese, E.J., Mattson, M.P. \& Calabrese, V. (2010). Dose response biology: the case of resveratrol. Human Experimental Toxicology, 29(12), 1034-1037. http://dx.doi.org/10.1177/0960327110383625.

Carrasco-Pozo, C., Mizgier, M.L., Speisky, H. \& Gotteland, M. (2011) Differential protective effects of quercetin, resveratrol, rutin and epigallocatechin gallate against mitochondrial dysfunction induced by indomethacin in Caco-2 cells. Chemico-Biological Interactions, 195, 199-205. http://dx.doi.org/10.1016/j.cbi.2011.12.007.

Collodel, G., Federico, M.G., Geminiani, M., Martini, S., Bonechi, C., Rossi, C., Figura, N. \& Moretti, E. (2010). Effect of trans-resveratrol on induced oxidative stress in human sperm and in rat germinal cells. Reproductive Toxicology, 31(2), 239-246. http://dx.doi.org/10.1016/j.reprotox.2010.11.010.

Cottart, CH. H., Antoine, V. N., Laguillier-Morizot, CH. \& Beaudeux, J. L. (2010). Resveratrol bioavailability and toxicity in human. Molecular Nutrition \& Food Research, 54:7-16. http://dx.doi.org/ 10.1002/mnfr.200900437.

de Lamirande, E. \& Gagnon, C. (1993). Human sperm hyperactivation and capacitation as parts of an oxidative process. Free Radicals in Biology and Medicine, 14, 157-166.

Dok-Go, H., Lee, K.H. \& Kim, H.J. (2003). Neuroprotective effects of antioxidative flavonoids, quercetin, (+)-dihydroquercetin and quercetin 3-methyl ether, isolated from Opuntia ficus indica var. saboten. Brain Research, 965(1-2), 130-136.

Donnelly, E.T., McClure, N. \& Lewis, S.E.M. (1999). The effect of ascorbate and $\alpha$-tocopherol supplementation in vitro on DNA integrity and hydrogen peroxide-induced DNA damage in human spermatozoa. Mutagenesis, 14(5), 505512. http://dx.doi.org/10.1093/mutage/14.5.505.

Ďuračka, M., Michalko, J., Matušíková, I. \& Tvrdá, E. (2016). Antioxidan effects of schizandra and bilberry extracts on male gametes. In Zborník referátov $z$ vedeckej konferencie: „Dendrologické dni v Arboréte Mlyn̆any SAV 2016“, 05.10.2016. Vieska nad Žitavou: Arborétum Mlyňany SAV, p. 41-46. ISBN 97880-89408-26-9.

Garcez, M.E., dos Santos Branco, C., Lara, L.V., Pasqualotto, F.F. \& Salvador, M. (2010). Effects of resveratrol supplementation on cryopreservation medium of human semen. Fertility and Sterility, 94, 2118-2121. http://dx.doi.org/ 10.1016/j.fertnstert.2010.01.058

Jamalan, M., Ghaffari, M.A., Hoseinzadeh, P., Hashemitabar, M. \& Zeinali, M. (2016). Human sperm quality and metal toxicants: protective effects of some flavonoids on male reproductive function. International Journal of Fertility and Sterility, 10(2), 215-223.

Katz, D.L., Doughty, K. \& Ali, A. (2011). Cocoa and chocolate in human health and disease. Antioxidants and Redox Signalling, 15, 2779-2811. http://dx.doi.org/10.1089/ars.2010.3697.

Khanduja, K.L., Verma, A. \& Bhardwaj, A. (2001). Impairment of human sperm motility and viability by quercetin is independent of lipid peroxidation. Andrologia, 33, 277-281.

Li, M.W., Yudin, A.I., VandeVoort, C.A., Sabeur, K., Primako , P. \& Overstreet, J. W. (1997). Inhibition of monkey sperm hyaluronidase activity and heterologous cumulus penetration by flavonoids. Biology of Reproduction, 56 1383-1389.

Mazzi, L., Geminiani, M., Collodel, G., Iacoponi, G., Martini, S., Boenchi, C. Rossi, C. \& Moretti, E. (2011). Quercetin and rutin: effects of two flavonoids on induced oxidative stress in human ejaculated sperm. Journal of the Sienna Academy of Science, 3, 22-26.

Mojica-Villegas, M.A., Izquierdo-Vega, J.A., Chamorro Cevallos, G. \& SanchezGuiterrez, M. (2014). Protective effect of resveratrol on biomarkers of oxidative stress induced by iron/ascorbate in mouse spermatozoa. Nutrients, 6, 489-503. http://dx.doi.org/10.3390/nu6020489.

Moretti, E., Mazzi, L., Terzuoli, G., Bonechi, C., Iacoponi, F., Martini, S., Rossi, C. \& Collodel, G. (2012). Effect of quercetin, rutin, naringenin and epicatechin on lipid peroxidation induced in human sperm. Reproductive Toxicology, 34 651-657. http://dx.doi.org/10.1016/j.reprotox.2012.10.002.

Naz, R.J. (2011). Can curcumin provide an ideal contraceptive? Molecular Reproduction and Development, 78, 116-123. http://dx.doi.org/10.1002/mrd.21276.

Pasqualotto, F.F., Garcez, M., Borges, E., Gupta, S., Salvador, M. \& Agarwal, A. (2006). Lipid peroxidation, superoxide dismutase, cata- lase levels and sperm motility: protective role of vitamin $\mathrm{C}$ and resveratrol prior to sperm cryopreservation. Fertility and Sterility, 86,

S446.

Purdy, P.H., Ericsson, S.A., Dodson, R.E., Sternes, K.L. \& Garner, D.L. (2004) Effects of the flavonoids, silibinin and catechin, on the motility of extended cooled caprine sperm. Small Ruminant Research, 55(1-3), 239-243 http://dx.doi.org/10.1016/j.smallrumres.2004.02.005.

Reddy, S. \& Aggarwal, B.B. (1994). Curcumin is a non-competitive and selective inhibitor of phosphorylase kinase. FEBS Letters, 341 (1), 19-22.

Rithaporn, T., Monga, M. \& Rajasekaran, M. (2003). Curcumin: a potential vaginal contraceptive. Contraception, 68, 219-223.

Rotem, R., Paz, G.F., Homonnai, Z.T., Kalina, M. \& Naor, Z. (1990a). Protein kinase $\mathrm{C}$ is present in human sperm: possible role in flagellar motility. Proceedings of the National Academy of Sciences, 87, 7305-7308.

Rotem, R., Paz, G.F., Homonnai, Z.T., Kalina, M. \& Naor, Z. (1990b). Further studies on the involvement of protein kinase $\mathrm{C}$ in human sperm flagellar motility. Endocrinology, 127, 2571-2577.

Salahshoor, M.R., Jalili, C., Khazaei, M. \& Khani, F. (2012). Effects of curcumin on reproductive parameters in male mice. Journal of Clinical Research in Paramedical Sciences, 1(3), 1-3.

Saleh, R.A. \& Agarwal, A. (2002). Oxidative stress and male infertility: from research bench to clinical practice. Journal of Andrology, 23(6), 737-752.

Sarlos, P., Molnar, A., Kokai, M., Gabor, G. \& Ratky, J. (2008). Comparative evaluation of the effect of antioxidants in the conservation of ram semen. Acta Veterinaria Hungarica, 50, 235-245.

Silva, E.C., Cajueiro, J.F., Silva, S.V., Soares, P.C. \& Guerra, M.M. (2012) Effect of antioxidants resveratrol and quercetin on in vitro evaluation of frozen ram sperm. Theriogenology, 77, 1722-1726. http://dx.doi.org/10.1016/j.theriogenology.2011.11.023.

Soleimanzadeh, A. \& Saberivand, A. (2013). Effect of curcumin on rat sperm morphology after the freeze-thawing process. Veterinary Research Forum, 4(3), 185-189. http://dx.doi.org/10.1016/S0093-691X(02)01231-1.

Taepongsorat, L., Tangpraprutgul, P., Kitana, N. \& Malaivijitnond, S. (2008) Stimulating effects of quercetin on sperm quality and reproductive organs in adult male rats. Asian Journal of Andrology, 10, 249-258.

Tvrdá, E., Halenár, M., Greifová, H., Mackovich, A., Hashim, F. \& Lukáč, N. (2016a). The effect of curcumin on cryopreserved bovine semen. Intrenational Journal of Biological, Biomolecular, Agricultural, Food and Biotechnological Engineering, 10(11), 669-673.

Tvrdá, E., Kňažická, Z., Bárdos, L., Massányi, P. \& Lukáč N. (2011). Impact of oxidative stress on male fertility - a review. Acta Veterinaria Hungarica, 59, 465 484. https://doi.org/10.1556/AVet.2011.034.

Tvrdá, E., Kováčik, A., Tušimová, E., Massányi, P. \& Lukáč, N. (2015a) Resveratrol offers protection to oxidative stress induced by ferrous ascorbate in bovine spermatozoa. Journal of Environmental Science and Health Part A, 50 1440-1451. http://dx.doi.org/10.1080/10934529.2015.1071153

Tvrdá, E., Lukáč, N., Lukáčová, J., Hashim, F. \& Massányi, P. (2015b). In vitro supplementation of resveratrol to bovine spermatozoa: effects on motility, viability and superoxide production. Journal of Microbiology, Biotechnology and Food Sciences, 4, 336-341. http://dx.doi.org/10.15414/jmbfs.2015.4.4.336341.

Tvrdá, E., Lukáč, N., Lukáčová, J., Jambor, T., Hashim, F. \& Massányi, P. (2014). Dose-and time-dependent in vitro effects of quercetin on bovine spermatozoa activity and superoxide production. Folia Veterinaria, 58, 224-231.

Tvrdá, E., Tušimová, E., Kováčik, A., Paál, D., Greifová, H., Abdramanov, A. \& Lukáč, N. (2016b). Curcumin has protective and antioxidant properties on bull spermatozoa subjected to induced oxidative stress. Animal Reproduction Science, 172, 10-20. http://dx.doi.org/10.1016/j.anireprosci.2016.06.008.

Tvrdá, E., Tušimová, E., Kováčik, A., Paál, D., Libová, L. \& Lukáč, N. (2016c) Protective effects of quercetin on selected oxidative biomarkers in bovine spermatozoa subjected to ferrous ascorbate. Reproduction in Domestic Animals 51(4), 524-537. http://dx.doi.org/10.1111/rda.12714. 